\title{
Alcohol Drinking and Cardiovascular Risk in a Population With High Mean Alcohol Consumption
}

\author{
Maryline Foerster, MD ${ }^{\mathrm{a}}$, Pedro Marques-Vidal, $\mathrm{MD}, \mathrm{PhD}^{\mathrm{a}, \mathrm{b}}$, Gerhard Gmel, $\mathrm{PhD}^{\mathrm{d}, \mathrm{e}}$, \\ Jean-Bernard Daeppen, MD ${ }^{\mathrm{d}}$, Jacques Cornuz, MD, MPH ${ }^{\mathrm{c}}$, Daniel Hayoz, MD ${ }^{\mathrm{f}}$, Alain Pécoud, MD ${ }^{\mathrm{c}}$, \\ Vincent Mooser, $\mathrm{MD}^{\mathrm{h}}$, Gérard Waeber, $\mathrm{MD}^{\mathrm{g}}$, Peter Vollenweider, $\mathrm{MD}^{\mathrm{g}}$, Fred Paccaud, $\mathrm{MD}^{\mathrm{a}}$, and \\ Nicolas Rodondi, MD, MAS ${ }^{\mathrm{c}, *}$
}

Moderate alcohol consumption has been associated with lower coronary artery disease (CAD) risk. However, data on the CAD risk associated with high alcohol consumption are conflicting. The aim of this study was to examine the impact of heavier drinking on 10-year CAD risk in a population with high mean alcohol consumption. In a population-based study of 5,769 adults (aged 35 to 75 years) without cardiovascular disease in Switzerland, 1-week alcohol consumption was categorized as 0,1 to 6,7 to 13,14 to 20,21 to 27,28 to 34 , and $\geq 35$ drinks/week or as nondrinkers ( 0 drinks/week), moderate ( 1 to 13 drinks/ week), high (14 to 34 drinks/week), and very high ( $\geq 35$ drinks/week). Blood pressure and lipids were measured, and 10-year CAD risk was calculated according to the Framingham risk score. Seventy-three percent $(n=4,214)$ of the participants consumed alcohol; $16 \%$ $(n=909)$ were high drinkers and $2 \%(n=119)$ very high drinkers. In multivariate analysis, increasing alcohol consumption was associated with higher high-density lipoprotein cholesterol (from a mean $\pm \mathrm{SE}$ of $1.57 \pm 0.01 \mathrm{mmol} / \mathrm{L}$ in nondrinkers to $1.88 \pm 0.03 \mathrm{mmol} / \mathrm{L}$ in very high drinkers); triglycerides $(1.17 \pm 1.01$ to $1.32 \pm 1.05 \mathrm{mmol} / \mathrm{L})$, and systolic and diastolic blood pressure $(127.4 \pm 0.4$ to $132.2 \pm 1.4 \mathrm{~mm} \mathrm{Hg}$ and $78.7 \pm 0.3$ to $81.7 \pm 0.9$ $\mathrm{mm} \mathrm{Hg}$, respectively) (all $\mathrm{p}$ values for trend $<0.001$ ). Ten-year CAD risk increased from $4.31 \pm 0.10 \%$ to $4.90 \pm 0.37 \%(\mathrm{p}=0.03)$ with alcohol use, with a J-shaped relation. Increasing wine consumption was more related to high-density lipoprotein cholesterol levels, whereas beer and spirits were related to increased triglyceride levels. In conclusion, as measured by 10-year CAD risk, the protective effect of alcohol consumption disappears in very high drinkers, because the beneficial increase in high-density lipoprotein cholesterol is offset by the increases in blood pressure levels. ㅇ 2009 Elsevier Inc. (Am J Cardiol 2009;103: 361-368)

The aim of this study was to assess the impact of heavier drinking on lipids, blood pressure, high-sensitivity C-reactive protein (hs-CRP), and 10-year coronary artery disease (CAD) risk in a population-based study in Switzerland in individuals with high mean alcohol consumption.

\section{Methods}

This cross-sectional study examined participants in the Cohorte Lausannoise (CoLaus) study, a population-based study of

\footnotetext{
${ }^{a}$ Institute of Social and Preventive Medicine, ${ }^{\mathrm{b}} \mathrm{CARDIOMET}$, and ${ }^{\mathrm{c} D e}$ partment of Ambulatory Care and Community Medicine, University of Lausanne; ${ }^{\mathrm{d}}$ Alcohol Treatment Center, Lausanne University Hospital; ${ }^{\mathrm{e} S w i s s}$ Institute for the Prevention of Alcohol and Drug Problems; Department of Medicine, Divisions of ${ }^{\mathrm{f}}$ Vascular Medicine and ${ }^{\mathrm{g}}$ Internal Medicine, Centre Hospitalier Universitaire Vaudois, Lausanne, Switzerland; and ${ }^{\mathrm{h}}$ Medical Genetics, GlaxoSmithKline, Philadelphia, Pennsylvania. Manuscript received July 10, 2008; revised manuscript received and accepted September 12, 2008.

This study was supported by research grants from the Faculty of Biology and Medicine of Lausanne, Switzerland, and from GlaxoSmithKline, Philadelphia, Pennsylvania.

*Corresponding author: Tel: 41-21-314-60-53; fax: 41-21-314-61-08.

E-mail address: nicolas.rodondi@hospvd.ch (N. Rodondi).
}

6,187 Caucasian community-dwelling men and women aged 35 to 75 years. Participants were selected from a random sample of all age-eligible adults living in the city of Lausanne, Switzerland (population 117,161). The details of eligibility criteria have been described previously. ${ }^{1}$ All participants gave written informed consent and the institutional review board in Lausanne approved the protocol. All participants were interviewed and examined at the clinical center from summer 2003 to spring 2006.

We further excluded 411 participants with cardiovascular disease, defined as a self-reported diagnosis of CAD (angina, previous myocardial infarction, percutaneous coronary angioplasty, or coronary artery bypass graft), stroke, or peripheral arterial disease. We also excluded 7 participants with missing variables for alcohol consumption. The final sample for our analysis was 5,769.

Participants reported whether they currently consumed alcohol and how many standard drinks they had consumed in the past 7 days, using the same method as other studies. ${ }^{2,3}$ A standard drink was defined as a glass of wine, a bottle of beer, or a shot of spirits, approximating 10 to $12 \mathrm{~g}$ of ethanol. ${ }^{4,5}$ Subjects were then categorized according to the number of drinks per week: 0,1 to 6,7 to 13,14 to 20,21 to 27,28 to 34 , and $\geq 35$ drinks/week. An alternative 4 -level 
Table 1

Participant characteristics according to alcohol consumption of the previous 7 days $(n=5,769)$

\begin{tabular}{|c|c|c|c|c|c|c|c|c|c|c|}
\hline \multirow[t]{2}{*}{ Characteristic } & \multirow[t]{2}{*}{ All Subjects } & \multicolumn{7}{|c|}{ Alcohol Use (Drinks in the Past Week) } & \multirow[t]{2}{*}{$\mathrm{p}$ Value } & \multirow{2}{*}{$\begin{array}{l}\mathrm{p} \text { Value } \\
\text { for Trend }\end{array}$} \\
\hline & & 0 & $1-6$ & $7-13$ & $14-20$ & $21-27$ & $28-34$ & $\geq 35$ & & \\
\hline $\mathrm{n}$ & & 1,555 & 2,051 & 1,135 & 567 & 241 & 101 & 119 & & \\
\hline Age (yrs) & $52.5 \pm 10.6$ & $52.1 \pm 10.8$ & $51.9 \pm 10.6$ & $52.8 \pm 10.7$ & $53.9 \pm 10.7$ & $53.2 \pm 9.8$ & $53.3 \pm 10.0$ & $54.0 \pm 10.7$ & $<0.001$ & 0.02 \\
\hline Women & $3,076(53 \%)$ & $1,134(73 \%)$ & $1,237(60 \%)$ & $483(43 \%)$ & $151(27 \%)$ & $45(19 \%)$ & $13(13 \%)$ & $13(11 \%)$ & $<0.001$ & $<0.001$ \\
\hline Physical activity (min/wk) & $64.3 \pm 50.9$ & $65.6 \pm 55.2$ & $62.2 \pm 41.5$ & $64.8 \pm 48.7$ & $67.5 \pm 60.1$ & $65.8 \pm 62.8$ & $65.8 \pm 77.6$ & $58.5 \pm 55.5$ & 0.20 & 0.47 \\
\hline Diabetes mellitus* & $252(4 \%)$ & $84(5 \%)$ & $75(4 \%)$ & $46(4 \%)$ & $21(4 \%)$ & $10(4 \%)$ & $8(8 \%)$ & $8(7 \%)$ & 0.06 & 0.10 \\
\hline Hypertension $^{\dagger}$ & $2,035(35 \%)$ & $546(35 \%)$ & $622(30 \%)$ & $372(33 \%)$ & $246(43 \%)$ & $116(48 \%)$ & $56(56 \%)$ & $77(65 \%)$ & $<0.001$ & $<0.001$ \\
\hline Body mass index $\left(\mathrm{kg} / \mathrm{m}^{2}\right)$ & $25.7 \pm 4.5$ & $26.5 \pm 0.1$ & $25.4 \pm 0.1$ & $25.3 \pm 0.1$ & $25.2 \pm 0.2$ & $25.5 \pm 0.3$ & $25.8 \pm 0.4$ & $25.8 \pm 0.4$ & $<0.001$ & 0.47 \\
\hline Education (yrs) & $13.1 \pm 4.3$ & $12.1 \pm 4.4$ & $13.6 \pm 4.2$ & $13.7 \pm 4.1$ & $13.0 \pm 4.6$ & $12.8 \pm 4.0$ & $13.6 \pm 4.9$ & $12.7 \pm 4.3$ & $<0.001$ & 0.53 \\
\hline Smoking status & & & & & & & & & $<0.001$ & $<0.001$ \\
\hline Never & $2,358(41 \%)$ & $828(53 \%)$ & $901(44 \%)$ & $386(34 \%)$ & $156(28 \%)$ & $50(21 \%)$ & $18(18 \%)$ & $19(16 \%)$ & & \\
\hline Former & $1,840(32 \%)$ & $388(25 \%)$ & $671(33 \%)$ & $420(37 \%)$ & $212(37 \%)$ & $76(32 \%)$ & $35(35 \%)$ & $38(32 \%)$ & & \\
\hline Current & $1,571(27 \%)$ & $339(22 \%)$ & $479(23 \%)$ & $329(29 \%)$ & $199(35 \%)$ & $115(48 \%)$ & $48(48 \%)$ & $62(52 \%)$ & & \\
\hline \multicolumn{11}{|c|}{ Self-reported alcohol consumption } \\
\hline \multicolumn{11}{|c|}{ Standard no. of drinks/wk } \\
\hline Wine & $6.9 \pm 7.1$ & & $2.7 \pm 1.7$ & $6.9 \pm 2.8$ & $12.0 \pm 4.5$ & $15.3 \pm 6.2$ & $20.8 \pm 8.0$ & $28.9 \pm 15.2$ & $<0.001$ & $<0.001$ \\
\hline Beer & $1.9 \pm 4.4$ & & $0.5 \pm 1.0$ & $1.4 \pm 2.2$ & $3.0 \pm 4.2$ & $5.3 \pm 6.1$ & $7.2 \pm 7.7$ & $13.6 \pm 13.6$ & $<0.001$ & $<0.001$ \\
\hline Spirits or liquor & $0.7 \pm 2.3$ & & $0.2 \pm 0.8$ & $0.7 \pm 1.7$ & $1.0 \pm 2.3$ & $2.2 \pm 3.7$ & $2.0 \pm 3.2$ & $3.9 \pm 8.1$ & $<0.001$ & $<0.001$ \\
\hline \multicolumn{11}{|l|}{$\%$ of total consumption } \\
\hline Wine & $76.7 \pm 31.0$ & & $79.3 \pm 33.3$ & $76.9 \pm 28.3$ & $75.5 \pm 28.2$ & $67.3 \pm 27.4$ & $69.1 \pm 26.6$ & $62.7 \pm 28.5$ & $<0.001$ & $<0.001$ \\
\hline Beer & $15.9 \pm 26.2$ & & $13.5 \pm 27.6$ & $15.4 \pm 22.8$ & $18.1 \pm 24.8$ & $23.1 \pm 26.5$ & $24.2 \pm 25.9$ & $29.0 \pm 27.5$ & $<0.001$ & $<0.001$ \\
\hline Spirits or liquor & $7.4 \pm 19.0$ & & $7.2 \pm 21.3$ & $7.7 \pm 17.9$ & $6.4 \pm 14.3$ & $9.7 \pm 15.6$ & $6.7 \pm 10.5$ & $8.4 \pm 17.3$ & 0.29 & 0.30 \\
\hline Abnormal total $\mathrm{CDT}^{*}$ & $330(6 \%)$ & $12(1 \%)$ & $30(2 \%)$ & $62(6 \%)$ & $77(14 \%)$ & $71(31 \%)$ & $28(28 \%)$ & $50(45 \%)$ & $<0.001$ & $<0.001$ \\
\hline Abnormal asialotransferrin ${ }^{\S}$ & $92(2 \%)$ & $4(0.3 \%)$ & $5(0.3 \%)$ & $11(1 \%)$ & $20(4 \%)$ & $21(9 \%)$ & $12(12 \%)$ & $19(17 \%)$ & $<0.001$ & $<0.001$ \\
\hline
\end{tabular}

Data are expressed as mean \pm SD or as number (percentage). Total percentages do not always exactly sum to $100 \%$ because of rounding

$*$ Defined as self-reported medical diagnosis and/or use of any hypoglycemic medication. ${ }^{16}$

${ }^{\dagger}$ Defined as self-reported medical diagnosis and use of antihypertensive medication and/or measured systolic blood pressure $\geq 140 \mathrm{~mm} \mathrm{Hg}$ and/or diastolic blood pressure $\geq 90 \mathrm{~mm} \mathrm{Hg}$.

* Expressed as a percentage of the total amount of serum transferrin and defined as abnormal if $\geq 1.63 \%$ according to the Central Laboratory of Lausanne University Hospital standards.

${ }^{\S}$ Expressed as a percentage of the total amount of serum transferrin and defined as abnormal if $>0 \% .{ }^{8}$ 
Table 2

Ten-year coronary artery disease risk, cardiovascular risk factors, and high-sensitivity C-reactive protein according to alcohol consumption in the previous 7 days ( $\mathrm{n}=5,769)$

\begin{tabular}{|c|c|c|c|c|c|c|c|c|c|c|c|c|}
\hline \multirow[t]{2}{*}{ Characteristic } & \multicolumn{7}{|c|}{ Alcohol Use (Drinks in the Past Week) } & \multirow{2}{*}{$\begin{array}{l}\mathrm{p} \text { Value by } \\
\text { ANOVA }\end{array}$} & \multirow{2}{*}{$\begin{array}{l}\mathrm{p} \text { Value for } \\
\text { Trend }\end{array}$} & \multirow{2}{*}{$\begin{array}{c}\mathrm{p}_{1} \\
\text { Value* }\end{array}$} & \multirow{2}{*}{$\begin{array}{c}\mathrm{p}_{2} \\
\text { Value* }\end{array}$} & \multirow{2}{*}{$\begin{array}{c}\mathrm{p}_{3} \\
\text { Value* }\end{array}$} \\
\hline & 0 & $1-6$ & $7-13$ & $14-20$ & $21-27$ & $28-34$ & $\geq 35$ & & & & & \\
\hline $\mathrm{n}$ & 1,555 & 2,051 & 1,135 & 567 & 241 & 101 & 119 & & & & & \\
\hline 10-year CAD risk & $3.13 \pm 0.14$ & $3.48 \pm 0.12$ & $4.69 \pm 0.16$ & $6.27 \pm 0.23$ & $7.39 \pm 0.35$ & $7.73 \pm 0.55$ & $8.52 \pm 0.50$ & $<0.001$ & $<0.001$ & $<0.001$ & $<0.001$ & $<0.001$ \\
\hline $\begin{array}{l}\text { Systolic blood pressure } \\
\text { (mm Hg) }\end{array}$ & $126.8 \pm 0.4$ & $125.3 \pm 0.4$ & $127.9 \pm 0.5$ & $133.3 \pm 0.7$ & $133.9 \pm 1.1$ & $135.5 \pm 1.7$ & $136.7 \pm 1.6$ & $<0.001$ & $<0.001$ & 0.26 & $<0.001$ & $<0.001$ \\
\hline $\begin{array}{l}\text { Diastolic blood pressure } \\
\qquad(\mathrm{mm} \mathrm{Hg})\end{array}$ & $78.7 \pm 0.3$ & $78.2 \pm 0.2$ & $79.2 \pm 0.3$ & $82.0 \pm 0.4$ & $83.0 \pm 0.7$ & $84.4 \pm 1.1$ & $83.4 \pm 1.0$ & $<0.001$ & $<0.001$ & 0.64 & $<0.001$ & $<0.001$ \\
\hline Total cholesterol (mmol/L) & $5.55 \pm 0.03$ & $5.54 \pm 0.02$ & $5.63 \pm 0.03$ & $5.70 \pm 0.04$ & $5.87 \pm 0.07$ & $6.03 \pm 0.10$ & $5.93 \pm 0.09$ & $<0.001$ & $<0.001$ & 0.36 & $<0.001$ & $<0.001$ \\
\hline HDL cholesterol (mmol/L) & $1.63 \pm 0.01$ & $1.66 \pm 0.01$ & $1.65 \pm 0.01$ & $1.63 \pm 0.02$ & $1.60 \pm 0.03$ & $1.65 \pm 0.04$ & $1.66 \pm 0.04$ & 0.18 & 0.80 & 0.04 & 0.79 & 0.41 \\
\hline LDL cholesterol $(\mathrm{mmol} / \mathrm{L})^{\dagger}$ & $3.32 \pm 0.02$ & $3.30 \pm 0.02$ & $3.37 \pm 0.03$ & $3.42 \pm 0.04$ & $3.53 \pm 0.06$ & $3.61 \pm 0.09$ & $3.38 \pm 0.09$ & $<0.001$ & 0.005 & 0.86 & $<0.001$ & 0.54 \\
\hline Triglycerides $(\mathrm{mmol} / \mathrm{L})^{\ddagger}$ & $1.14 \pm 1.01$ & $1.10 \pm 1.01$ & $1.19 \pm 1.02$ & $1.25 \pm 1.02$ & $1.44 \pm 1.03$ & $1.43 \pm 1.05$ & $1.60 \pm 1.05$ & $<0.001$ & $<0.001$ & 0.58 & $<0.001$ & $<0.001$ \\
\hline $\begin{array}{l}\text { Total cholesterol/HDL } \\
\text { cholesterol } \\
\text { hs-CRP }(\mathrm{mg} / \mathrm{L})^{\ddagger \S}\end{array}$ & $3.62 \pm 0.03$ & $3.56 \pm 0.03$ & $3.64 \pm 0.03$ & $3.72 \pm 0.05$ & $3.93 \pm 0.07$ & $3.87 \pm 0.11$ & $3.88 \pm 0.10$ & $<0.001$ & $<0.001$ & 0.30 & $<0.001$ & 0.02 \\
\hline Women & $1.58 \pm 1.03$ & $1.27 \pm 1.03$ & $1.17 \pm 1.05$ & $1.27 \pm 1.10$ & $1.31 \pm 1.18$ & $0.95 \pm 1.37$ & $0.94 \pm 1.37$ & $<0.001$ & 0.08 & $<0.001$ & 0.008 & 0.11 \\
\hline Men & $1.33 \pm 1.05$ & $1.07 \pm 1.04$ & $1.16 \pm 1.04$ & $1.49 \pm 1.05$ & $1.39 \pm 1.08$ & $1.55 \pm 1.12$ & $1.62 \pm 1.11$ & $<0.001$ & $<0.001$ & 0.002 & 0.14 & 0.09 \\
\hline
\end{tabular}

Data are expressed as mean $\pm \mathrm{SE}$

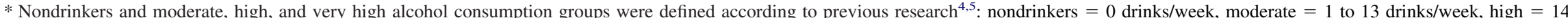

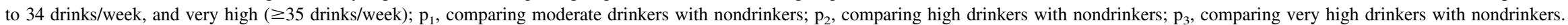
${ }^{\dagger} \mathrm{LDL}$ cholesterol values were not calculated when triglycerides were $>4.5 \mathrm{mmol} / \mathrm{L}$.

₹ Triglycerides and hs-CRP levels were log transformed for statistical analysis because the distributions were skewed.

$\S$ The $p$ value for interaction by gender was statistically significant for hs-CRP $(p=0.03)$ in the multivariate model.

ANOVA $=$ analysis of variance. 
Table 3

Adjusted 10-year coronary artery disease risk, cardiovascular risk factors, and high-sensitivity C-reactive protein according to alcohol consumption in the previous 7 days $(\mathrm{n}=5,769)$

\begin{tabular}{|c|c|c|c|c|c|c|c|c|c|c|c|c|}
\hline \multirow[t]{2}{*}{ Characteristic } & \multicolumn{7}{|c|}{ Alcohol Use (Drinks in the Past Week) } & \multirow{2}{*}{$\begin{array}{l}\mathrm{p} \text { Value by } \\
\text { ANOVA }\end{array}$} & \multirow{2}{*}{$\begin{array}{l}\mathrm{p} \text { Value for } \\
\text { Trend }\end{array}$} & \multirow{2}{*}{$\begin{array}{c}\mathrm{p}_{1} \\
\text { Value* }\end{array}$} & \multirow{2}{*}{$\begin{array}{c}\mathrm{p}_{2} \\
\text { Value* }\end{array}$} & \multirow{2}{*}{$\begin{array}{c}\mathrm{p}_{3} \\
\text { Value* }\end{array}$} \\
\hline & 0 & $1-6$ & $7-13$ & $14-20$ & $21-27$ & $28-34$ & $\geq 35$ & & & & & \\
\hline $\mathrm{n}$ & 1,555 & 2,051 & 1,135 & 567 & 241 & 101 & 119 & & & & & \\
\hline 10-year CAD risk & $4.31 \pm 0.10$ & $4.19 \pm 0.09$ & $4.03 \pm 0.12$ & $4.25 \pm 0.17$ & $4.56 \pm 0.26$ & $4.60 \pm 0.39$ & $4.90 \pm 0.37$ & $<0.001$ & 0.03 & 0.16 & 0.70 & 0.12 \\
\hline $\begin{array}{l}\text { Systolic blood pressure (mm } \\
\qquad \mathrm{Hg})^{\dagger}\end{array}$ & $127.4 \pm 0.4$ & $126.4 \pm 0.3$ & $127.5 \pm 0.4$ & $130.9 \pm 0.6$ & $131.4 \pm 1.0$ & $132.7 \pm 1.5$ & $132.2 \pm 1.4$ & $<0.001$ & $<0.001$ & 0.16 & $<0.001$ & 0.001 \\
\hline $\begin{array}{l}\text { Diastolic blood pressure } \\
(\mathrm{mm} \mathrm{Hg})^{\dagger}\end{array}$ & $78.7 \pm 0.3$ & $78.7 \pm 0.2$ & $79.2 \pm 0.3$ & $81.3 \pm 0.4$ & $82.2 \pm 0.7$ & $83.4 \pm 1.0$ & $81.7 \pm 0.9$ & $<0.001$ & $<0.001$ & 0.67 & $<0.001$ & 0.002 \\
\hline Total cholesterol $(\mathrm{mmol} / \mathrm{L})^{\ddagger}$ & $5.52 \pm 0.03$ & $5.56 \pm 0.02$ & $5.65 \pm 0.03$ & $5.69 \pm 0.04$ & $5.88 \pm 0.06$ & $6.04 \pm 0.10$ & $5.95 \pm 0.09$ & $<0.001$ & $<0.001$ & 0.03 & $<0.001$ & $<0.001$ \\
\hline HDL cholesterol $(\mathrm{mmol} / \mathrm{L})^{\ddagger}$ & $1.57 \pm 0.01$ & $1.62 \pm 0.01$ & $1.67 \pm 0.01$ & $1.73 \pm 0.02$ & $1.76 \pm 0.02$ & $1.84 \pm 0.04$ & $1.88 \pm 0.03$ & $<0.001$ & $<0.001$ & $<0.001$ & $<0.001$ & $<0.001$ \\
\hline LDL cholesterol $(\mathrm{mmol} / \mathrm{L})^{\ddagger, \S}$ & $3.33 \pm 0.02$ & $3.34 \pm 0.02$ & $3.37 \pm 0.03$ & $3.35 \pm 0.04$ & $3.45 \pm 0.06$ & $3.52 \pm 0.09$ & $3.31 \pm 0.08$ & $<0.001$ & 0.27 & 0.62 & 0.15 & 0.72 \\
\hline Triglycerides $(\mathrm{mmol} / \mathrm{L})^{\ddagger} \|^{\prime}$ & $1.17 \pm 1.01$ & $1.15 \pm 1.01$ & $1.17 \pm 1.01$ & $1.16 \pm 1.02$ & $1.27 \pm 1.03$ & $1.24 \pm 1.05$ & $1.32 \pm 1.05$ & $<0.001$ & $<0.001$ & 0.31 & 0.44 & 0.01 \\
\hline $\begin{array}{l}\text { Total cholesterol/HDL } \\
\text { cholesterol } \\
\end{array}$ & $3.73 \pm 0.03$ & $3.67 \pm 0.02$ & $3.58 \pm 0.03$ & $3.48 \pm 0.04$ & $3.56 \pm 0.07$ & $3.46 \pm 0.10$ & $3.41 \pm 0.09$ & $<0.001$ & $<0.001$ & 0.003 & $<0.001$ & 0.001 \\
\hline \multicolumn{13}{|l|}{ hs-CRP mg/L", } \\
\hline Men & $1.32 \pm 1.05$ & $1.14 \pm 1.04$ & $\begin{array}{l}1.20 \pm 1.05 \\
1.19 \pm 1.04\end{array}$ & $\begin{array}{l}1.50 \pm 1.08 \\
1.42 \pm 1.05\end{array}$ & $\begin{array}{l}1.45 \pm 1.10 \\
1.25 \pm 1.07\end{array}$ & $\begin{array}{l}0.90 \pm 1.32 \\
1.40 \pm 1.11\end{array}$ & $\begin{array}{l}1.09 \pm 1.32 \\
1.34 \pm 1.10\end{array}$ & $\begin{array}{l}<0.001 \\
<0.001\end{array}$ & $\begin{array}{l}0.19 \\
0.21\end{array}$ & $\begin{array}{l}0.10 \\
0.02\end{array}$ & $\begin{array}{l}0.53 \\
0.57\end{array}$ & $\begin{array}{l}0.34 \\
0.86\end{array}$ \\
\hline
\end{tabular}

Data are expressed as mean \pm SE and were adjusted for age, gender, education, units of weekly physical activity, tobacco use, and BMI.

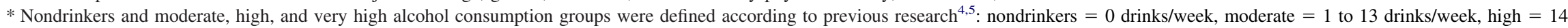

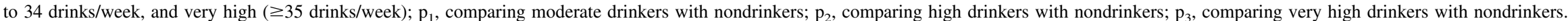

${ }^{\dagger}$ Blood pressure values were adjusted for age, gender, education, units of weekly physical activity, BMI, antihypertensive medication, and tobacco use.

${ }^{*}$ Lipid values were adjusted for age, gender, education, units of weekly physical activity, BMI, statins, and tobacco use.

${ }^{\S} \mathrm{LDL}$ cholesterol values were not calculated when triglycerides were $>4.5 \mathrm{mmol} / \mathrm{L}$.

"I Triglyceride and hs-CRP levels were log transformed for statistical analysis because the distributions were skewed.

${ }^{\mathbb{I}}$ The $\mathrm{p}$ value for interaction by gender was statistically significant for hs-CRP $(\mathrm{p}=0.03)$ in the multivariate model.

$\mathrm{BMI}=$ body mass index. Other abbreviation as in Table 2 . 
classification was used: nondrinkers (0 drinks/week), moderate (1 to 13 drinks/week), high (14 to 34 drinks/week), and very high ( $\geq 35$ drinks/week) alcohol consumption., ${ }^{4,6}$ Three different types of alcoholic beverages were considered in this study: wine, beer, and spirits. ${ }^{7}$ Self-reported alcohol consumption was partially validated by measuring the blood levels of carbohydrate-deficient transferrin (CDT; a combination of asialotransferrin and disialotransferrin). CDT separation was obtained by capillary electrophoresis on a P/ACE 5510 System (Beckman Coulter Instruments, Nyon, Switzerland). Normal CDT was defined as $<1.63 \%$, a cut-off value that included the 97.5th percentile of the abstinent and of the "social drinker" populations (consumption $<30 \mathrm{~g}$ ethanol/day). Normal asialotransferrin was defined as a level of $0 \%$, because detectable values enable the identification of chronic and abusive alcohol consumption. ${ }^{8}$ We examined the relation between alcohol consumption and CDT and asialotransferrin. We did not exclude participants with high CDT who reported no alcohol consumption, because the specificity of CDT is $92 \%$ for alcohol consumption. $^{8}$

According to their smoking histories, participants were classified as never, current, or former smokers (if they had stopped smoking). Blood pressure and heart rate were measured by trained field investigators, 3 times in the left arm in the seated position, after $\geq 10$ minutes of rest, using an Omron HEM-907 automated oscillometric sphygmomanometer (Omron Matsusaka Company, Ltd., Kyoto, Japan), with an appropriately sized cuff. The second and third measurements were averaged to reduce variability, as recommended. ${ }^{9}$ Hypertension was defined as self-report and the use of antihypertensive medications and/or measured systolic blood pressure $\geq 140 \mathrm{~mm} \mathrm{Hg}$ and/or diastolic blood pressure $\geq 90 \mathrm{~mm} \mathrm{Hg}$. Total and high-density lipoprotein (HDL) cholesterol were measured after overnight fasting by enzymatic methods (cholesterol oxidase; Roche Diagnostics $\mathrm{GmbH}$, Mannheim, Germany). Low-density lipoprotein (LDL) cholesterol was calculated by the Friedewald equation. Triglycerides were assessed by glycerol phosphate oxidase-p-aminophenazone. Glucose was measured by glucose dehydrogenase. Hs-CRP was assessed by immunoassay (HS Latex; Diagnostic Products Corporation, Los Angeles, California). Most biologic assays were performed by the Central Laboratory of Lausanne University Hospital, which is regularly checked for performance and quality. As in other studies, ${ }^{10}$ we calculated 10-year CAD risk for each participant using the Framingham risk score. ${ }^{11}$ This version of the Framingham risk score includes diabetes mellitus and estimates the risk for CAD (angina pectoris, recognized and unrecognized myocardial infarction, coronary insufficiency, and CAD death). The Framingham risk score has the best prospective validation in several American ${ }^{12}$ and international $^{13}$ cohorts. In this version of the Framingham risk score, diabetes was defined as fasting blood glucose level $\geq 7.8 \mathrm{mmol} / \mathrm{L}$ or receiving antidiabetic treatment.

Self-reported level of education was used as a proxy for socioeconomic status, a validated proxy measure in Switzerland. ${ }^{14}$ Physical activity was assessed by questions focusing on walking and other types of exercises in minutes per week. Weight was measured in kilograms with $0.1 \mathrm{~kg}$ precision using a Seca scale (Seca, Reinach, Switzerland)

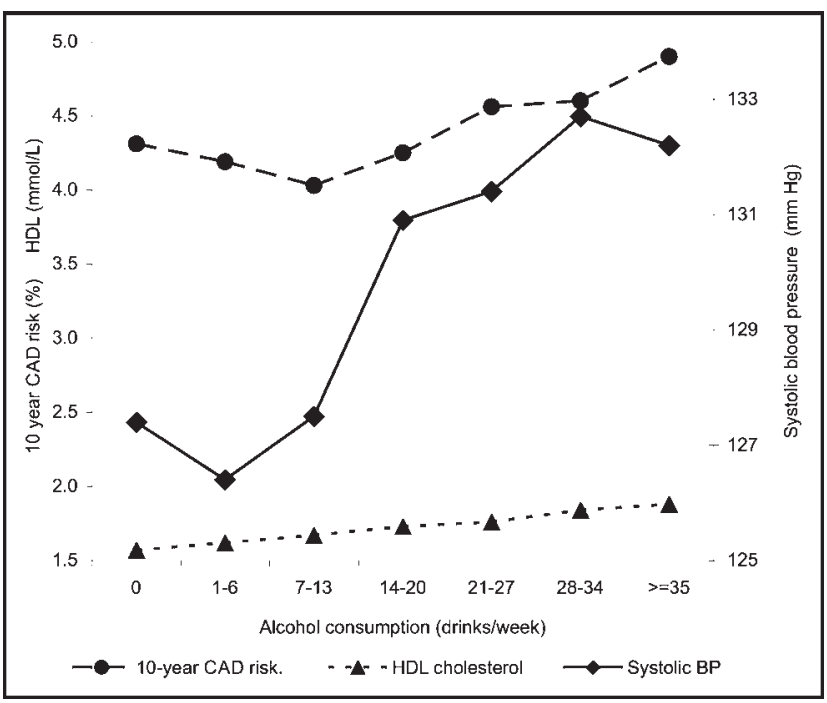

Figure 1. Association between alcohol consumption, cardiovascular risk factors, and 10-year CAD risk. HDL cholesterol, systolic blood pressure (BP), and 10-year CAD risk according to last week alcohol consumption. Values are adjusted for age, gender, education, units of weekly physical activity, tobacco use, body mass index, statins (for HDL cholesterol), and antihypertensive medications (for systolic BP). Alcohol consumption was associated with increased HDL cholesterol ( $\mathrm{p}$ for trend $<0.001$ ), systolic $\mathrm{BP}$ ( $\mathrm{p}$ for trend $<0.001$ ), and 10-year CAD risk ( $\mathrm{p}$ for trend $=0.03$ ).

that was regularly calibrated. Height was measured using a Seca height gauge with a precision of $0.5 \mathrm{~cm}$.

Statistical analyses were conducted using Stata version 9.2 (StataCorp LP, College Station, Texas). Results are reported as mean $\pm \mathrm{SE}$ or as numbers and percentages of subjects. A $p$ value $<0.05$ was considered to represent statistical significance. Linear regression models were used to assess the unadjusted associations between alcohol categories and blood pressure, lipids, hs-CRP, and 10-year CAD risk. To assess other factors independently associated with alcohol consumption, the multivariate models further included potential confounders identified by comparing baseline characteristics across alcohol use categories: age, gender, education, tobacco use, and body mass index, as in other studies. ${ }^{15}$ Antihypertensive medications and statins were also included as confounders for blood pressure and lipid levels, respectively. Physical activity was also included as a potential confounder on the basis of clinical plausibility, despite a lack of significant differences. We used chi-square tests for trend for categorical variables and tests for trend for continuous variables across alcohol use categories. ${ }^{5}$ Because a significant gender-by-alcohol interaction was found for hs-CRP ( $p$ for interaction $=0.03$ ), the results for hs-CRP were stratified by gender. A gender-byalcohol interaction was also found for LDL cholesterol ( $\mathrm{p}=$ 0.03 ), but no gender stratification was performed because no significant gender-by-alcohol interactions were found for other lipid values. The effects of the type of alcoholic beverage on cardiovascular risk factors, 10 -year CAD risk, and hs-CRP were assessed, generating 3 variables, wine, beer, and spirits, corresponding to their consumption in drinks per week. If no drink was consumed, the variable was set to 0 . The 3 variables for the type of alcoholic beverage were used simultaneously in a multivariate model testing 
Table 4

Adjusted 10-year coronary artery disease risk, cardiovascular risk factors, and high sensitivity C-reactive protein according to beverage type consumption in the previous 7 days

\begin{tabular}{lccc}
\hline Variable & Wine & Beer & Spirits \\
\hline 10-year CAD risk & $0.01 \pm 0.01$ & $0.00 \pm 0.01$ & $0.02 \pm 0.01$ \\
Blood pressure (mm Hg) ${ }^{\dagger}$ & & & 0.64 \\
$\quad$ Systolic & $0.05 \pm 0.02^{\ddagger}$ & $0.07 \pm 0.02^{\S}$ & $0.01 \pm 0.01$ \\
$\quad$ Diastolic & $0.08 \pm 0.02^{\S}$ & $0.06 \pm 0.02^{\S}$ & $0.00 \pm 0.02$ \\
Lipids (mmol/L) & & & 0.04 \\
Total cholesterol & $0.10 \pm 0.02^{\S}$ & $0.06 \pm 0.02^{\ddagger}$ & $0.02 \pm 0.02$ \\
HDL cholesterol & $0.18 \pm 0.02^{\S}$ & $0.05 \pm 0.02^{\ddagger}$ & $0.01 \pm 0.01$ \\
LDL cholesterol & $0.02 \pm 0.02$ & $0.00 \pm 0.02$ & $0.00 \pm 0.02$ \\
Triglycerides & $-0.01 \pm 0.02$ & $0.07 \pm 0.02^{\S}$ & $0.04 \pm 0.02^{* *}$ \\
hs-CRP (mg/L) & & & 0.02 \\
Women & $-0.05 \pm 0.02^{* *}$ & $0.00 \pm 0.02$ & 0.01 \\
Men & $-0.03 \pm 0.02$ & $0.04 \pm 0.02$ & 0.005 \\
\hline
\end{tabular}

Data are expressed as standardized slopes per drink consumed per week $\pm \mathrm{SE}^{7}$ and were adjusted for age, gender, education, units of weekly physical activity, tobacco use, and BMI. Only participants with alcohol consumption $\geq 7$ drinks/week were included in this analysis.

$*$ Test for the homogeneity of slopes (wine $=$ beer $=$ spirits).

$\dagger$ Blood pressure values were adjusted for age, gender, education, units of weekly physical activity, BMI, antihypertensive medication, and tobacco use.

${ }^{*} \mathrm{p}<0.01$.

$\S \mathrm{p}<0.001$.

" Lipid values were adjusted for age, gender, education, units of weekly physical activity, BMI, statins, and tobacco use.

${ }^{\text {II }} \mathrm{LDL}$ cholesterol values were not calculated when triglycerides were $>4.5 \mathrm{mmol} / \mathrm{L}$.

\# Triglyceride and hs-CRP levels were log transformed for statistical analysis because the distributions were skewed.

$* * \mathrm{p}<0.05$.

Abbreviations as in Tables 2 and 3.

the hypothesis of the equality of the different standardized regression coefficients for each beverage type. ${ }^{7}$ The standardized regression coefficients represent the change in the dependent variables that resulted from a change of $1 \mathrm{SD}$ in each of the independent variables.

\section{Results}

The baseline characteristics of the participants are listed in Table 1. About three quarters of the participants (73\%) consumed alcohol, and more than half $(55 \%)$ had moderate consumption (1 to 13 drinks/week); 16\% had high consumption (14 to 34 drinks/week), and $2 \%$ had very high consumption ( $\geq 35$ drinks/week). Wine was the most frequent beverage type consumed, and beer consumption was predominant in men. Women were less likely to be in the high or very high alcohol consumption groups and, overall, tended to drink less alcohol than men. Higher alcohol consumption was associated with increased levels of CDT and asialotransferrin, tobacco smoking, and hypertension (all $\mathrm{p}$ values for trend $<0.001)$.

In unadjusted analysis (Table 2), increasing alcohol use was associated with increasing systolic and diastolic blood pressure, total cholesterol, the ratio of total to HDL cholesterol, LDL cholesterol, triglycerides, and 10-year CAD risk. A significant positive relation between alcohol use and hs-CRP was also found in men, but not in women (inverse nonsignificant trend). No significant relation was found between alcohol consumption and HDL cholesterol level.

In multivariate analysis, alcohol consumption was associated with increased systolic and diastolic blood pressure, total and HDL cholesterol, the ratio of total to HDL cholesterol, triglycerides, and 10-year CAD risk (Table 3).
Conversely, no significant trend was found for LDL cholesterol levels, nor for hs-CRP levels, but only in men. In women, hs-CRP was inversely associated with alcohol consumption, although the levels observed in the 2 highest consumption groups should be interpreted with caution because of the small numbers (Table 1). Restricting the analysis to nonsmoking participants provided similar results (not shown). The confounding factors responsible for the changes in the relation between alcohol consumption and cardiovascular risk factors were as follows: for HDL cholesterol, body mass index, physical activity and smoking; for LDL cholesterol, gender and age; and for hs-CRP, body mass index in women and smoking (major effect) and age in men. The association between alcohol consumption and 10-year CAD risk and systolic blood pressure showed a J-shaped relation (Figure 1), while the levels of HDL cholesterol increased monotonically with the level of alcohol consumption. Excluding subjects with diabetes led to similar results. Removing from the multivariate model tobacco use (which is used in the Framingham risk score) yielded a similar pattern of association between alcohol consumption and 10-year CAD risk.

The effects of wine, beer, and spirits on each cardiovascular risk factor and 10-year CAD risk were assessed by multivariate analysis separately for each beverage type (Table 4). The standardized regression slopes correspond to the variation in cardiovascular risk factors, 10-year CAD risk, or hs-CRP for 1 additional drink per week for each beverage type. The relation between alcohol and 10-year CAD risk score did not differ by beverage type. For HDL cholesterol, increased consumption of wine had a stronger effect than that of beer, and spirits had no effect. Similarly, wine and beer but not spirits had an impact on blood pressure and 
total cholesterol (all p values of equality of slopes $<0.04$ ). The level of triglycerides increased with beer or spirits consumption but not with wine. No statistically significant differences regarding the effects of each type of alcoholic beverage were found for other factors.

\section{Discussion}

In this population-based study including a substantial proportion of high drinkers, increasing alcohol consumption was associated with higher HDL cholesterol levels but also with increased levels of total cholesterol and triglycerides and increased blood pressure values, resulting in a $\mathbf{J}$-shaped relation with 10-year CAD risk. The protective effect of alcohol on CAD risk disappears because the increase in blood pressure offsets the benefits of the increase in HDL cholesterol.

A previous cross-sectional study conducted in women in the United Kingdom ${ }^{5}$ found a linear decrease in 10-year CAD risk with average alcohol consumption up to 21 drinks/week but could not examine the effects of higher amounts because of the very small number of participants reporting higher consumption. A study that pooled cohort studies conducted in Denmark ${ }^{17}$ showed a lower risk for death from CAD with increasing alcohol consumption, although the effects were different according to beverage type: beyond 21 drinks/week, a further decrease of CAD risk was found only for wine, but higher consumption was not further stratified. The Danish study also showed that wine drinkers had lower mortality from both CAD and cancer than nonwine drinkers. The discrepancy between our results and those from the United Kingdom ${ }^{5}$ and Denmark ${ }^{17}$ for wine drinkers might be explained by the wider range of alcohol consumption (through 35 drinks/week) included in our study: more subjects were consequently classified as heavy drinkers (i.e., more subjects had high CAD risk). In Denmark (as in other northern European countries), these results might also partially be related to the different (and probably healthier) lifestyle of the wine drinkers. ${ }^{18}$

In the present study, we found that the J-shaped relation between increasing alcohol consumption and 10-year CAD risk was most likely related to the moving balance of the effects of alcohol consumption. The main mechanism is related to HDL cholesterol and blood pressure: as alcohol consumption increases, the protective effect of an increasing HDL cholesterol level is progressively outweighed by the deleterious effect of increased blood pressure levels. A previous prospective cohort study conducted in Scottish men $^{2}$ suggested that the high CAD mortality in heavy drinkers ( $>15$ drinks/week) was related to the effect of blood pressure.

The increase in HDL cholesterol level with total alcohol consumption has been previously described ${ }^{7,19}$ and is presumed to be the main mechanism for the protective effect of moderate alcohol consumption on CAD. ${ }^{19}$ In this study, increasing wine consumption was more related to increased HDL cholesterol level. The direct link between wine and HDL cholesterol level is in agreement with some studies ${ }^{7,20}$ but not with others. ${ }^{21}$ Possible main confounders include the higher socioeconomic status or the healthier behaviors of wine drinkers ${ }^{21}$ or the fact that the major beverage type consumed by a population, wine in this population, has often been shown to have the strongest and most significant association with cardiovascular risk factors. ${ }^{22}$

In the present data, alcohol consumption was positively related to triglyceride levels, in agreement with some studies $^{23}$ but not with others. ${ }^{5,20}$ Multivariate analysis showed no effect of wine on triglycerides but did show effects of spirits and beer, similar to previous studies. ${ }^{7,21}$ However, residual confounding due to incomplete adjustment cannot be ruled out, and further studies are needed to better assess the specific effects of beverage types on triglyceride levels.

The direct association between the level of alcohol consumption and blood pressure is in agreement with previous research, ${ }^{7,20}$ and this study provides additional information on the effect of high levels of alcohol consumption. Whether the type of alcoholic beverage matters is still debated. $^{7,24}$ In the present study, wine and beer exerted similar effects on blood pressure.

In the present data, an inverse relation between alcohol consumption and hs-CRP levels was found in women, albeit not statistically significant, whereas a more complex Jshaped relation was found in men. The decrease in hs-CRP levels with increased alcohol consumption in women is in agreement with previous studies, whereas the lack of decrease in male alcohol drinkers does not reproduce previous reports, ${ }^{25,26}$ which might be related to the highest consumption groups in our population. Indeed, in previous studies, ${ }^{25}$ the inverse relation between alcohol consumption and hsCRP levels was found in drinkers of 1 to 7 drinks/week, whereas an increase in hs-CRP levels was found for higher levels of consumption. Overall, our data suggest that the beneficial effect of alcohol consumption on hs-CRP levels might actually disappear and become deleterious for levels of consumption $>2$ drinks/day. We found no major effect of beverage type, in agreement with a study in Chile. ${ }^{27}$

Our study had several limitations. First, alcohol consumption was self-reported, which might lead to the selective misclassification of heavy drinkers. However, data on alcohol consumption from food-frequency questionnaires and 1-week diet records have been shown to be well correlated ${ }^{28}$ and most studies on alcohol consumption have relied on self-reported data. ${ }^{2,7}$ Moreover, the present study used CDT levels to help validate reported alcohol consumption. The use of a recall period limited to 1 week before the survey interview might also lead to the misclassification of some participants who do consume alcohol but who did not drink in the previous 7 days. Although this may artificially increase the proportion of abstainers, short recall periods have been consistently shown to be better than long periods to assess consumption at higher levels. ${ }^{29}$ Another limitation is that our study did not capture drinking patterns, such as binge drinking. Finally, the 10 -year CAD risk did not account for other potential beneficial effects of alcohol on variables that are not included in the Framingham risk score, such as fibrinogen. ${ }^{30}$

1. Rodondi N, Cornuz J, Marques-Vidal P, Butler J, Hayoz D, Pécoud A, Paccaud F, Waeber G, Vollenweider P. Aspirin use for the primary prevention of coronary heart disease: a population-based study in Switzerland. Prev Med 2008;46:137-144. 
2. Hart CL, Smith GD, Hole DJ, Hawthorne VM. Alcohol consumption and mortality from all causes, coronary heart disease, and stroke: results from a prospective cohort study of Scottish men with 21 years of follow up. BMJ 1999;318:1725-1729.

3. Marques-Vidal P, Dias CM. Trends and determinants of alcohol consumption in Portugal: results from the national health surveys 1995 to 1996 and 1998 to 1999. Alcohol Clin Exp Res 2005;29:89-97.

4. Dufour MC. What is moderate drinking? Defining "drinks" and drinking levels. Alcohol Res Health 1999;23:5-14.

5. Nanchahal K, Ashton WD, Wood DA. Alcohol consumption, metabolic cardiovascular risk factors and hypertension in women. Int $J$ Epidemiol 2000;29:57-64.

6. Rehm JT, Bondy SJ, Sempos CT, Vuong CV. Alcohol consumption and coronary heart disease morbidity and mortality. Am J Epidemiol 1997; 146:495-501.

7. Marques-Vidal P, Montaye M, Haas B, Bingham A, Evans A, JuhanVague I, Ferrières J, Luc G, Amouyel P, Arveiler D, et al. Relationships between alcoholic beverages and cardiovascular risk factor levels in middle-aged men, the PRIME Study. Atherosclerosis 2001;157: $431-440$.

8. Legros FJ, Nuyens V, Baudoux M, Zouaoui BK, Ruelle JL, Colicis J, Cantraine F, Henry JP. Use of capillary zone electrophoresis for differentiating excessive from moderate alcohol consumption. Clin Chem 2003;49:440-449.

9. Rodondi N, Pletcher MJ, Liu K, Hulley SB, Sidney S. Marijuana use, diet, body mass index, and cardiovascular risk factors (from the CARDIA study). Am J Cardiol 2006;98:478-484.

10. Denes P, Larson JC, Lloyd-Jones DM, Prineas RJ, Greenland P. Major and minor ECG abnormalities in asymptomatic women and risk of cardiovascular events and mortality. JAMA 2007;297:978-985.

11. Wilson PW, D’Agostino RB, Levy D, Belanger AM, Silbershatz H, Kannel WB. Prediction of coronary heart disease using risk factor categories. Circulation 1998;97:1837-1847.

12. D'Agostino RB Sr, Grundy S, Sullivan LM, Wilson P. Validation of the Framingham coronary heart disease prediction scores: results of a multiple ethnic groups investigation. JAMA 2001;286:180-187.

13. Liu J, Hong Y, D'Agostino RB Sr, Wu Z, Wang W, Sun J, Wilson PW, Kannel WB, Zhao D. Predictive value for the Chinese population of the Framingham CHD risk assessment tool compared with the Chinese Multi-Provincial Cohort Study. JAMA 2004;291:2591-2599.

14. Bopp M, Minder CE. Mortality by education in German speaking Switzerland, 1990-1997: results from the Swiss National Cohort. Int $J$ Epidemiol 2003;32:346-354.

15. Mukamal KJ, Chiuve SE, Rimm EB. Alcohol consumption and risk for coronary heart disease in men with healthy lifestyles. Arch Intern Med 2006;166:2145-2150.

16. de Rekeneire N, Rooks RN, Simonsick EM, Shorr RI, Kuller LH, Schwartz AV, Harris TB. Racial differences in glycemic control in a well-functioning older diabetic population: findings from the Health, Aging and Body Composition Study. Diabetes Care 2003;26:19861992.

17. Gronbaek M, Becker U, Johansen D, Gottschau A, Schnohr P, Hein HO, Jensen G, Sorensen TI. Type of alcohol consumed and mortality from all causes, coronary heart disease, and cancer. Ann Intern Med 2000;133:411-419.

18. Tjønneland AM, Gronbaek M, Stripp C, Overvad K. Wine intake and diet in a random sample of 48763 Danish men and women. Am J Clin Nutr 1999;69:49-54.

19. Gaziano JM, Buring JE, Breslow JL, Goldhaber SZ, Rosner B, VanDenburgh M, Willett W, Hennekens CH. Moderate alcohol intake, increased levels of high-density lipoprotein and its subfractions, and decreased risk of myocardial infarction. N Engl J Med 1993;329: $1829-1834$.

20. Marques-Vidal P, Cambou JP, Nicaud V, Luc G, Evans A, Arveiler D, Bingham A, Cambien F. Cardiovascular risk factors and alcohol consumption in France and Northern Ireland. Atherosclerosis 1995;115: $225-232$.

21. Ruidavets JB, Ducimetière P, Arveiler D, Amouyel P, Bingham A, Wagner A, Cottel D, Perret B, Ferrières J. Types of alcoholic beverages and blood lipids in a French population. J Epidemiol Community Health 2002;56:24-28.

22. Rimm EB, Klatsky A, Grobbee D, Stampfer MJ. Review of moderate alcohol consumption and reduced risk of coronary heart disease: is the effect due to beer, wine, or spirits? BMJ 1996;312:731-736.

23. Rimm EB, Williams P, Fosher K, Criqui M, Stampfer MJ. Moderate alcohol intake and lower risk of coronary heart disease: meta-analysis of effects on lipids and haemostatic factors. BMJ 1999;319:15231528.

24. Stranges S, Wu T, Dorn JM, Freudenheim JL, Muti P, Farinaro E, Russell M, Nochajski TH, Trevisan M. Relationship of alcohol drinking pattern to risk of hypertension: a population-based study. Hypertension 2004:44:813-819.

25. Volpato S, Pahor M, Ferrucci L, Simonsick EM, Guralnik JM, Kritchevsky SB, Fellin R, Harris TB. Relationship of alcohol intake with inflammatory markers and plasminogen activator inhibitor- 1 in well-functioning older adults: the Health, Aging, and Body Composition study. Circulation 2004;109:607-612.

26. Mukamal KJ, Cushman M, Mittleman MA, Tracy RP, Siscovick DS. Alcohol consumption and inflammatory markers in older adults: the Cardiovascular Health Study. Atherosclerosis 2004;173:79-87.

27. Mezzano D, Leighton F, Martínez C, Marshall G, Cuevas A, Castillo O, Panes O, Munoz B, Pérez DD, Mizón C, et al. Complementary effects of Mediterranean diet and moderate red wine intake on haemostatic cardiovascular risk factors. Eur J Clin Nutr 2001;55:444451.

28. Giovannucci E, Colditz G, Stampfer MJ, Rimm EB, Litin L, Sampson $\mathrm{L}$, Willett WC. The assessment of alcohol consumption by a simple self-administered questionnaire. Am J Epidemiol 1991;133:810-817.

29. Leigh BC. Using daily reports to measure drinking and drinking patterns. J Subst Abuse 2000;12:51-65.

30. Mukamal KJ, Jadhav PP, D'Agostino RB, Massaro JM, Mittleman MA, Lipinska I, Sutherland PA, Matheney T, Levy D, Wilson PW, et al. Alcohol consumption and hemostatic factors: analysis of the Framingham Offspring Cohort. Circulation 2001;104:1367-1373. 